Working Paper 10-42

Business Economic Series 07

October 2010
Departamento de Economía de la Empresa Universidad Carlos III de Madrid

Calle Madrid, 126

28903 Getafe (Spain)

Fax (34-91) 6249607

\title{
Current Marketing Practices and Market Orientation in the Context of an Emerging Economy: the Case of Uruguay *
}

\author{
Nora Lado ${ }^{1}$, Lola C. Duque ${ }^{2}$ and Daniel Alvarez Bassi ${ }^{3}$
}

\begin{abstract}
This research explores the link between contemporary marketing practices, market orientation and business performance in Uruguay, an emergent country that has recovered from an economic crisis. These approaches seem to be related, but there is no existing evidence to confirm this impression. Lessons can be learned from understanding how effective is the adoption of marketing practices under a crisis scenario. Using data from interviews with 143 micro and small enterprises' managers, we identify three clusters dependant on the combination of marketing practices: a multi-marketing cluster, a medium-level relationship marketing cluster and a transactional cluster. A model relating market orientation components and various performance measures is tested for the three clusters, showing that the multi-marketing and transactional clusters are more effective in translating efforts and resources into business outcomes.
\end{abstract}

Keywords: Contemporary marketing practices, Market orientation, Performance, Clusters, Structural equation modeling, Uruguay

\footnotetext{
${ }^{1}$ Nora Lado is associate professor of marketing in the Department of Business Administration at Carlos III University of Madrid. E-mail: nora@eco.uc3m.es

${ }^{2}$ Lola C. Duque is assistant professor of marketing in the Department of Business Administration at Carlos III University of Madrid. E-mail: Iduque@emp.uc3m.es

${ }^{3}$ Daniel Alvarez Bassi is a PhD candidate in management at University of Deusto and lecturer of marketing at the Catholic University of Uruguay. E-mail: dalvarez@ucu.edu.uy
} 


\section{Introduction}

The aim of marketing as an academic discipline is to contribute to advances in marketing practice by providing an understanding of the current marketing approaches, their effectiveness, and by offering ideas for new or modified marketing practices. But how far do the marketing practices already adopted by firms reflect the contributions and concerns of marketing as an academic discipline? How are they related with other academic approaches as market orientation? How are they translated into firm outcomes? And finally, how effective can they be under different contexts and conditions?

This paper explores the relationship between marketing practices, market orientation and business performance, by linking the theoretical framework of marketing practices proposed by Coviello, Brodie, and Munro (1997; 2000) with market orientation (MO) theory (Kohli, and Jaworski 1990; Jaworski, and Kohli 1993) and their impact on performance measures. Although certain approaches to marketing, such as database marketing and interaction marketing may at first appear to meet the MO goals more successfully, there is no existing evidence to confirm this impression. There is a need for studies linking marketing practices with performance (Brodie, Coviello, and Winklhofer 2008).

Given the variation in business fabrics and entrepreneurial cultures across the globe, it is important to follow the adoption and direction of management trends in different cultures, both from businesses in resource-rich developed countries and those in developing countries. In the context of the current global financial crisis, for example, many lessons can be learned from the reactions and strategies adopted by businesses in different countries. Practices in distant cultures can provide a model both to businesses already operating there and those hoping to do so in the future. An example of how this can work is given by Moshe, Torres, and Lado (2009), who analyze the reactions of bank customers to the marketing tactics developed by Uruguayan banks to weather the profound financial crisis that hit their economy in 2001. Their research is likely to be of interest to banks and financial institutions in other markets currently faced with a financial crisis. It may 
also enrich the academic discipline of marketing if findings can be extended and generalized to other markets (Hubbard, Vetter, and Little 1998; Brodie, and Danaher 2000).

Uruguay provides an interesting case of study because it is a country that has overcome a profound financial and economic crisis from which it has emerged in an exemplary manner. How did micro and small enterprises adapt their marketing practices to face that crisis? A second objective of this paper is to provide an update of the marketing practices that micro and small enterprises in Uruguay are using in order to identify which ones have been more effective. This analysis will shed light on the effectiveness of the marketing practices adoption under a crisis scenario.

We start with a review of marketing practices and market orientation literature. Then, we present the methodology and the identified clusters of firms by their combination of marketing practices adoption. Next, a model relating market orientation and firm performance is tested for each cluster. Our main finding is that in times of crises extreme marketing practices produce better results than "middle of the road" approaches.

\section{Marketing Practices, Market Orientation and Performance}

\section{Contemporary Marketing Practices}

Coviello, Brodie, and Munro (1997; 2000) suggest a classification scheme for contemporary marketing practices that explains how businesses relate with the market. Certain questions arise from the literature review. For example, is Coviello et al's model valid for the Uruguayan context? How can it be adapted to different firm environments? What kind of model achieves firm performance gains?

Coviello, Brodie, Danaher and Wesley (2002) and Brodie, Coviello, Brookes, and Little (1997) use their previous studies as a basis to develop other classification schemes to clarify and 
define content and concept of relationship marketing, and to identify its different forms. According to these authors, any attempt to understand and analyze the content of marketing in the current context is hampered by (i) the variety of terms used to describe and define marketing, (ii) the different units or levels of analysis used as a reference by the various schools of research and, (iii) the view that certain types of marketing are more appropriate than others for certain sectors or industries. To overcome these obstacles, they make a content analysis on the marketing terms used in previous studies and identify the three common topics as exchange, relationships and managerial issues. The first two are the most hotly-debated pair of topics in the recent literature.

Coviello et al's marketing classification scheme (1997; 2000) has two main dimensions: relational exchange and managerial issues. In view of the disparity of opinion regarding exchange versus relationships as the pivotal point of marketing, this paper adopts the relational exchange dimension, which combines the properties of the transactional approach and the relational approach, and a second dimension to capture issues relating to the management and direction of marketing strategies as per Ambler (1994) and Houston, Gasemheimer and Maskulka (1992).

The findings of that study enable the identification of two main perspectives with respect to marketing: the transactional perspective and the relational perspective. These are accompanied by four separate, but not mutually exclusive, marketing approaches- whose main characteristics are summarized below:

1. The transactional marketing perspective includes: transaction marketing, which uses the marketing mix to achieve customer satisfaction (AMA, 1985) and create discrete economic transactions. Although these transactions may extend over time, they are handled separately.

2. The relationship marketing perspective includes:

a) Database marketing. This covers the use of all those IT-based marketing tools designed to develop personalized relationships with customers. 
b) Interaction marketing. This involves personal relationships, and a switch from products and the firm as the units of focus to people, organizations, and the social process that holds the actors together and sustains their relationships. These relationships are based on social interaction, and involve elements of trust, mutual orientation, dependence, satisfaction, commitment and adaptation.

c) Network marketing. This is the development of relationships between businesses enabling multi-party coordination of activities to obtain mutual benefits, exchange of resources, etc.

Coviello et al (2002) extend their study to a sample of firms from the US, Canada, Nordic countries and New Zealand. Authors working in this stream of research belong to the “Contemporary Marketing Practices" (CMP) Group, who are extending this research to a variety of contexts such as Argentina (Pels, and Brodie 2004) or Russia (Wagner 2005) to name a few.

Among those focusing on small businesses, Coviello's et al (2006) study deserves special mention. They note a lack of specific research in which market orientation is related to marketing practices and firm performance. To address this gap, the present study also incorporates the case of businesses (mainly micro and small enterprises) operating in the context of an emerging economy.

\section{Market Orientation}

Kohli and Jaworski (1990) view MO as revolving around three behavioral factors or goals that organizations need to pursue: (i) the generation of market intelligence about current and future consumer needs, (ii) the dissemination of that intelligence throughout all the departments and functions of the organization, and (iii) the development of response capacity.

Recently, some important contributions have been made to the literature on MO levels and their impact on performance (Matsuno, and Mentzer 2000; Noble, Sinha, and Kumar 2002) and as a function of business strategy. Nevertheless, there has been no analysis of whether the different 
marketing approaches proposed and validated by Coviello et al. imply variation in MO levels across firms.

Although there have been some studies investigating the market orientation-performance relationship in small businesses (Pelham 2000; Pelham, and Wilson 1996), most studies concentrate only in small manufacturing firms. The response to clients' needs involves more customization in service firms than in manufacturing firms. Customization to implement the market orientation concept implies higher costs for service firms compared to manufacturing firms. The different relationship between market orientation and performance in service firms versus manufacturing firms have been corroborated by a recent meta-analysis study (Kirca et al 2005). More research about the impact of market orientation in small service firm is needed.

Key questions remain to be answered. Do market oriented businesses tend to rely more heavily on relationship or transactional marketing practices? Market orientation has been defined as a culture permeating the entire organization (Narver, and Slater 1990; Slater, and Narver 1994). In that case, the market orientation level should condition marketing practices. Nevertheless, several authors claim that market orientation is the implementation of the concept of marketing (Lado, Maydeu, and Rivera 1998). Thus, it can be hypothesized that it is the firm's marketing approach that conditions its market orientation level. This paper leans towards this view.

\section{Methodology}

\section{Sample and Data Collection}

Data were obtained through questionnaires addressed to company directors and by means of personal interviews. The study used a convenience sample covering a large number of Uruguayan firms from a wide range of service sector branches. The process of questionnaire pre-testing and application of the final revision took place between May 2006 and January 2007. 
A total of 143 service firms compose this study's sample. Five industries (hotel, real estate, clothing, gastronomic and bookshops) account for over half of the sample. This sample is weighted towards businesses that Uruguayan and Mercosur standards classify as micro and small enterprises. Thirty-six percent of the sample has fewer than five employees (micro-enterprises), 35 percent between five and 19 (micro and small businesses), 20 percent between 20 and 99 and nice percent of the sample consists of firms with more than 100 employees. Eighty-six percent of the firms are more than three years old.

It is worth mentioning that only a very small proportion of the firms (less than three percent of the sample) operate exclusively B2B. Just over half (53 percent) serve both end customers and other businesses (B2B), and 44 percent focus exclusively on end customers.

\section{Measures}

Marketing practices and performance indicators were measured by the instrument used by Coviello, Brodie, Danaher, and Johnston (2002), and Coviello et al. (2000). Market Orientation measures are based on the study by Lado, Maydeu-Olivares, and Rivera (1998) and by Lado, and Maydeu-Olivares (2001). Appendix 1 presents marketing practices measures. They were slightly adapted to the Uruguayan context by repeated pretesting of draft questionnaires. Measures were translated into Spanish using the "back-translation" method to ensure the accuracy of the scale items.

\section{Questionnaire}

The questionnaire was designed to fit different types of businesses, particularly small ones, and for respondents with no specialist knowledge of marketing. This is an interesting adaptation of the questionnaires used by the CMP Group, where respondents are required to have a reasonable knowledge of marketing.

The starting point was the questionnaire used by Coviello et al (2000), and after pre-tests to validate content and constructs in the Uruguayan context, two of the original dimensions were 
removed. The nine original dimensions are: purpose of the exchange, nature of the communication, type of contact, duration of the exchange, formality of the exchange, managerial intention, managerial focus, managerial investment and managerial level. "Formality of the exchange" was excluded due to repeated comprehension difficulties, and "Managerial level" was omitted as being unsuitable for the size of firms being surveyed.

Thus, the study uses seven marketing dimensions with questions designed to measure the following four aspects of marketing practice: transaction marketing, database marketing, interaction marketing and network marketing. Respondents indicate their level of use of each marketing tool on a Likert scale ranging from 1 to 5.

The final questionnaire consisted of seven blocks related to: firm characteristics, firm's marketing activities, firm's allocation of marketing resources, firm's market orientation level, firm environment, firm's business performance, and respondent characteristics.

\section{Analyses}

In order to explore the link between contemporary marketing practices, market orientation and performance of firms in the Uruguayan context we develop various analyses that can be described as a two-stage process. First, we use cluster analysis to identify firms' patterns by marketing practices. Then, we characterize profiles of each cluster. And second, a path model linking market orientation and firm performance is estimated for the overall sample and for each cluster. We use cluster analysis and analysis of variance (ANOVA) with the Bonferroni test (SPSS 14) to evaluate differences between clusters, and structural equation modeling based in the PLS algorithm (PLS-Graph) to estimate the proposed path model .

\section{Results and Discussion}

\section{Cluster Analysis of Marketing Approaches}


We constructed a formative index for every firm, for each marketing approach: transaction, database, interaction and network following the suggestion of Coviello et al (2006). These indices, in a 35-points scale and that are reported in Table 1, were used to group the firms by their use of marketing practices. We evaluated solutions of different number of clusters using conglomerate analysis and the three-cluster solution was chosen. This solution offers meaningful interpretation and this type of division has been used in previous studies (e.g. Coviello et al 2002; Dadzie et al 2008; Pels et al 2004). To validate the three-cluster solution we check for differences (significant at the 5 percent level) between variables related to market orientation and performance in each cluster. Table 2 (first column) shows the mean value of the indices for the different variables. Three out of the four MO components (customer orientation, environmental orientation and inter-functional coordination) are significantly different in the three clusters. Environmental orientation (the fourth MO component) is significantly lower for cluster 3. The overall MO index is also significantly different for the three clusters. We evaluate four firm performance variables (customer retention, customer recruitment, turnover and overall profitability). Customer recruitment is significantly different in the three clusters, while the three remaining variables are significantly lower for cluster 3. These differences support the three-cluster solution. Next, we present the profile of these three clusters.

Cluster 1: "Multi-marketing". Firms in this cluster exhibit intense usage of all four marketing approaches. With 60 cases, it is the largest group and accounts for 42 percent of the sample. In terms of activity, the main feature of this cluster is a large proportion of restaurants. Hotels, real estate agencies and clothing firms are present, but they are more highly represented in the other two clusters. In terms of workforce numbers, this cluster has a high concentration of businesses within 5-99 workers. Firms in this cluster serve both, B2B and B2C markets. In resource investment terms, firms in this cluster invest the largest amounts in sales promotion, product promotion, integrated marketing communication strategy, customer and environment data management, one-to-one marketing resources, service improvements, customer retention, customer 
management systems, e-commerce resources and web data. In terms of its environmental characteristics, the multi-marketing cluster appears to operate in more modern, less stable and rapidly developing industries of a nature, characterized by major technological requirements, market growth and new product availability.

Cluster 2: "Medium-level relationship marketing". Firms in this cluster show medium-level usage of relationship marketing tools. Forty-seven firms belong to this cluster and account for 33 percent of the sample. It has a high concentration of hotels, real estate businesses, micro enterprises and young businesses (less than three years of age) and some over 30 years of age. Firms in this cluster serve both types of markets and also of businesses targeting end customers. Their level of resource investment classifies as medium, since they invest less in marketing than cluster 1 but more than cluster 3.

Cluster 3: "Transactional Marketing". Firms in this cluster are mainly oriented towards transaction marketing. Thirty-six firms belong to this cluster, accounting for 25 percent of the sample. In terms of economic activity, this cluster is characterized by and over-representation of clothing firms, few hotels and real estate businesses, and an absence of certain branches of activity such as gastronomy and furniture sales. This cluster, as cluster 2, has a high concentration of micro enterprises. It also shows a high concentration of businesses targeting end customers. Most of the firms in this cluster are in the range of 11-30 year of age. Firms in this cluster operate in more stable environments, with fewer technological demands and probably have less capital requirements. Firms in this cluster claim to invest fewer resources in marketing and customer services. The exception is for sales promotion, where they appear to concentrate their marketing efforts.

Marketing practices by cluster. Table 1 shows the degree in which each of the marketing practices is used by firms in the three clusters. Firms are categorized in low, medium or high degree based on the cutoffs used in previous studies (Dazie et al 2008; Pels and Brodie 2004).

Table 1 here. 
Cluster 1 surpasses the other two clusters in the use of transaction, database, interaction and network marketing. The firms in this cluster are in the high usage level category, showing their multi-marketing focus. All the scores are about 30 in a 35-point scale and the highest score in the firms' use of interaction marketing. Firms in cluster 2 are in the high to medium categories in most of the marketing approaches, but in a less proportion than firms in cluster 1, especially lower for network marketing. Firms in cluster 3 show low indices for all the marketing practices, and the lowest network marketing. Interestingly, however, cluster 3's firms score very high in transaction marketing.

Looking at the table as a whole, we can conclude that the Uruguayan micro and small enterprises over-use the transaction marketing approach. Most of the firms in the three clusters score high or medium in this marketing practice. The interaction marketing approach is also used, but in a less extent by firms in cluster 3 .

\section{Model of the MO Impact on Firm Performance by Cluster}

The impact of MO on different measures of business performance has been corroborated by a recent meta-analysis (Matsuno, and Mentzer 2000; Noble, Sinha, and Kumar 2002; Kirca et al 2005). Nevertheless, there has been no previous research of whether the different marketing practice typologies proposed and validated by Coviello et al $(1997,2000)$ imply variation in MO levels across firms or differences in the impact of market orientation components on performance.

Having sorted the firms into clusters, the next step is to estimate a model relating the MO components with firm performance measures. The aim is to assess how the impact of customer orientation, competence orientation, environmental orientation and inter-functional coordination on firm performance vary for the three different clusters. The selected performance measures are 
similar to those studied by Coviello et at (2006): customer retention, customer recruitment, turnover and overall profitability.

Figure 1 depicts the proposed model and the estimations for the pooled sample. We test the model employing SEM as suggested by Brodie et al (2008), since it allows for a more comprehensive analysis of consequences of marketing practices.

Model estimation. We estimate the path model using the PLS (Partial Least Squares) algorithm, which is robust to conditions of non-normality and small sample size. To evaluate the quality of the model estimation we followed Hulland (1999). First, we checked for the psychometric properties of measures and constructs (see Table 1). Composite reliability (CR) indices are close or above the recommended .70 for the pooled sample and for the clusters, indicating construct reliability. Discriminant validity is tested by comparing the average variance extracted (AVE) of each construct with the shared variance between constructs. The AVE's squared root for each construct exceeds its shared variance with other constructs. The high values of AVEs confirm that average communality of measures in the model are above or close to the recommended threshold of .70 , which provides discriminant validity.

Second, the model fit is evaluated in terms of explained variance of the dependent variables. Figure 1 presents the model estimation for the pooled sample and Table 2 shows estimations for the clusters. The model explains high percentages of the four dependent variables of the model: 61 percent of customer recruitment, 62 percent of turnover, 77 percent of overall profitability and 36 percent of customer retention. These percentages vary for the cluster's estimations. This table also presents the average communality of the measures in the model, which are in most of the cases higher than .70. For comparative purposes we did not remove items to improve reliability in the cluster estimations. Table 3 shows the estimations' standardized coefficients and their significance ( $t$ values come from Bootstrap re-sampling procedure with 200 samples).

Figure 1 and Table 2 here. 
Interpretation of the Model Estimation. Table 3 presents the estimation summary for the pooled sample and the three clusters. From the estimation for the pooled sample we observe that only one impact is significant at the five percent level: customer orientation on customer retention. But looking at the estimation for the three subsamples (clusters) we observe different patterns. The most oriented-market firms (cluster 1) obtain better results in terms of customer retention and recruitment, followed for those of cluster 3. Interestingly, although firms in cluster 2 are more market-oriented than firms in cluster 3 they are not being more effective in translating efforts to outcomes as firms in cluster 3. Firms in cluster 1 and cluster 3 are also more effective in translating customer retention and recruitment into overall profitability and sales turnover than firms in cluster 2. Few relationships in the model resulted to be significant for firms in cluster 2 compared to the other clusters estimations.

Table 3 here.

\section{Conclusions}

This study explores the link between marketing practices, market orientation and business performance in Uruguay, an emergent country that has recovered from an economic crisis. We first evaluate how micro and small enterprises are adopting different types of marketing practices. Then we identify clusters of firms by the specific combination of those practices and describe their profiles. A general conceptual model of the relationships between MO components and performance measures is tested for the different clusters.

This research partially validates the marketing practices classification scheme for the Uruguayan context. The main findings reveal a strong correlation between database marketing, interaction marketing and network marketing. This suggests that firms with a more intense usage of 
database marketing tools also use more interaction and network marketing tools. These findings are consistent with those obtained by Coviello et al (2003) and Auruskeviciene et al (2007). The correlation between these marketing practices and transactional marketing is weak.

We identify three groups of firms characterized by the types of marketing they practice. The first group, which we label the multi-marketing cluster, is composed of firms who declare high usage of transaction, interaction, database and network marketing practices, and obtain high scores in the various MO components. This integral approach responds to the active environment they operate in (high technological requirements, market growth and innovation). The second group, the medium-level relationship marketing cluster, obtains medium level scores on marketing practices’ and MO components' indicators. Firms in the third group, the transactional marketing cluster, practice transaction marketing in more stable markets and concentrate their investment in sales promotion. Despite of their low scores in most of the MO components, firms in this cluster maintain personal contact with their customers. These findings are consistent with those obtained by Pels et al (2004) for Argentina.

Firms in the transactional marketing cluster invest less resources in relationship marketing than firms in the other clusters, with very little or no use of personal communication marketing tools. Nevertheless, they do not neglect their interpersonal relationships with customers. This may be related with a phenomenon reported by Pels (in a comparative study of marketing practices between B2B businesses in the Argentine, New Zealand and the USA) regarding the influence of the Latin culture on customer-firm relationships.

Uruguayan managers of micro and small enterprises apply different marketing practices in parallel. They combine traditional transaction marketing practices with more sophisticated relationship marketing practices. They do so in a completely natural way, with no analysis of the benefits associated to each type of practice.

The results show that some managers, particularly those in the multi-marketing cluster, 
make significant use of both transaction and relationship marketing practices. Nevertheless, we also identify opportunities for firm performance improvements. Marketing training for managers of micro and small enterprises might help to raise awareness of the benefits to be obtained from extra tools (especially in relationship marketing) that could be used to achieve performance gains in the various contexts in which these businesses operate. For example, firms in the transactional marketing cluster show a weak use of database marketing tools as well as network marketing tools. These firms would benefit from improving their manager's formation on the efficiency and the efficacy of database implementation. It could also be beneficial to generate awareness of the advantages of identifying and cooperating with strategic partners developing win-win strategies.

Regarding the relationships between marketing practices and firm performance, we find a low correlation between the global firm performance indicator and the transaction marketing indicator. In contrast, there is a high positive correlation between the firm performance indicator and the various forms of relationship marketing. Firms that implement and apply relationship marketing practices tend to show better firm performance. Strong correlation is also found between the firm performance indicator and market orientation. Firms with high market orientation levels show better firm performance levels, which is consistent with findings obtained in previous research (Kirca et al 2005, Kara et al 2005, Horng and Cheng-Hui 1998).

Interesting findings emerge when the model of relationships between the various MO components and firm performance is tested. The results show that market orientation, and most of its components, have a positive and significant impact on customer recruitment and retention, and also on economic performance in firms declaring intense usage of the various types of marketing practices (multi-marketing cluster). Firms that diversify their marketing practices by applying relationship marketing as well as transactional marketing practices obtain the greatest benefit from market orientation. Firms that prioritize the use of transaction marketing (transactional marketing cluster) also achieve a positive impact on customer retention from their low levels of customer 
orientation and orientation towards competitors. Despite not being highly market-oriented, these firms appear to have optimized their resources in such a way as to obtain a positive impact on customer retention. It is worth recalling that although this cluster is characterized by transaction marketing practices, managers still maintain personal contact with customers. This contrasts with firms declaring medium-level usage of relationship marketing practices and MO, which obtain only a significant impact of inter-functional coordination on customer retention.

In conclusion, the results from the Uruguayan context seem to indicate that in times of crisis, extreme marketing practices produce better results than a "middle of the road" approach. 


\section{References}

Auruskevicienè, Viltè, Rita Kuvykaitè and Vida Skudienè, (2007). "Relationship and Transactional Marketing Integration Aspects," Commerce and Engineering Decisions, Engineering Economics, 4 (54), 78-86.

Ambler, Tim (1994). "The Relational Paradigm: A Synthesis," in "Relationship Marketing: Theory, Methods, and Application," Sheth and Parvatiyar Eds., G.A: Centre of Relationship Marketing, Atlanta.

Brodie, Roderick J., Nicole E. Coviello, and Heidi Winklhofer (2008). "Contemporary Marketing Practices Research Program: A Review of the First Decade," Journal of Business \& Industrial Marketing, 23 (2), 84-94.

Brodie, Roderick J., Nicole E. Coviello, R. W. Brookes and, V. Little (1997). "Towards a Paradigm Shift in Marketing? An Examination of Current Marketing Practices," Journal of Marketing Management, 13 (5), 383-406.

Brodie, Roderick J., and Peter J. Danaher (2000). "Building Models for Marketing Decisions: Improving Empirical Procedures," International Journal of Research in Marketing, 17 (2), 135-139.

Coviello, Nicole E., Roderick J. Brodie and Hugh J. Munro (1997). "Understanding Contemporary Marketing: Development of a Classification Scheme," Journal of Marketing Management, $13,501-522$.

Coviello, Nicole E., Roderick J. Brodie, Peter J. Danaher and Wesley, J. Johnston (2002). "How Firms Relate to Their Markets: An Empirical Examination of Contemporary Marketing Practices," Journal of Marketing, July, 66 (3), 33-46.

Coviello, Nicole E.., Roderick J. Brodie, R. W. Brookes and Roger A. Palmer (2003). "Assessing the Role of e-Marketing in Contemporary Marketing Practice," Journal of Marketing Management, 19 (7/8), 857-881.

Coviello, Nicole E., Heidi Winkhofer and Karla Hamilton (2006). "Marketing Practices and Performance of Small Service Firms: An Examination in the Tourism Accommodation Sector," Journal of Service Research, August, 9 (1), 35-38.

Coviello, Nicole E., Roderick J. Brodie and Hugh J. Munro (2000). "An Investigation of Marketing Practice by Firm Size,” Journal of Business Venturing, 15, 523-545.

Dadzie, K., Wesly J. Johnston and Jaqueline Pels (2008). "Business-to Business Marketing Practices in Emerging Economies: West Africa and Argentina Benchmarked with the United States," Journal of Business \& Industrial Marketing, 23 (2), 115-23.

Horng, Shun-Ching and Arthur Cheng-Hsui Chen (1998). "Market Orientation of Small and Medium-Sized Firms in Taiwan,” Journal of Small Business Management, 36 (3), 79-85.

Houston, Franklin S., Jule B. Gassenheimer and James M. Maskulka (1992). Marketing Exchange Transactions and Relationships. Westport: Quorum Books. 
Hubbard, Raymond, Daniel E. Vetter, and Eldon L. Little (1998). "Replication in Strategic Management: Scientific Testing for Validity, Generalizability and Usefulness," Strategic Management Journal, 19 (3), 243-254.

Hulland, John (1999). "Use of Partial Least Squares (PLS) in Strategic Management Research: A Review of Four Recent Studies,” Strategic Management Journal, 20 (2), 195-204.

Jaworski, Bernard J., and Ajay K. Kohli (1993). "Market Orientation: Antecedents and Consequences," Journal of Marketing, 57 (July), 53-70.

Kara, Ali, John E. Spillan and Oscar W. DeShields Jr. (2005). "The Effect of a Market Orientation on Business Performance: A Study of Small-Sized Service Retailers Using MARKOR Scale," Journal of Small Business Management, 43 (2), 105-118.

Kirca, Ahmet H., Satish Jayachandran and William O. Bearden (2005). "Market Orientation: A Meta-Analytic Review and Assessment of Its Antecedents and Impact on Performance," Journal of Marketing, 69 ( 2), 24-41.

Kohli, Ajay K. and Bernard J. Jaworski (1990). "Market Orientation: the Construct, Research Propositions, and Managerial Implications," Journal of Marketing, 54 (April), 1-18.

Lado, Nora and Albert Maydeu-Olivares (2001). "Exploring the link between Market Orientation and Innovation in the European and U.S. Insurance Markets," International Marketing Review, 18 (2), 130-144.

Lado, Nora, Albert Maydeu-Olivares and Jaime Rivera (1998). "Measuring Market Orientation in Several Populations: A Structural Equations Approach," European Journal of Marketing, 32 (1/2), 23-39.

Matsuno, Ken and John T. Mentzer, (2000). "The Effects of Strategy Type on the Market Orientation-Performance Relationship," Journal of Marketing, 64 (4), 1-17.

Narver, John C. and Stanley F. Slater (1990). "The Effect of a Market Orientation on Business Profitability," Journal of Marketing, 54 (October), 20-35.

Noble, Charles H.,Rajiv K. Sinha, and Ajith Kumar (2002)."Market Orientation and Alternative Strategic Orientations: A Longitudinal Assessment of Performance Implications," Journal of Marketing, 66 (4), 25-40.

Pelham, Alfred M. and David T Wilson (1996). "A Longitudinal Study of the Impact of Market Structure, Firm Structure, Strategy, and Market Orientation Culture on Dimensions of Small-Firm Performance," Journal of the Academy of Marketing Science, 24 (1), 27-43.

Pelham, Alfred M. (2000). "Market Orientation and Other Potential Influences on Performance in Small and Medium-Sized Manufacturing Firms," Journal of Small Business Management, 38 (1), 48-67.

Pels, Jaqueline and Roderick J. Brodie (2004)."Profiling Marketing Practice in an Emerging Economy: The Argentine Case," Journal of Global Marketing, 17 (1), 67-91.

Pels, Jaqueline, Roderick J. Brodie and Wesly J. Johnston (2004)."Benchmarking Business-toBusiness Practices in Emerging and Developed Economies: Argentina Compared to the USA and New Zealand”, Journal of Business and Industrial Marketing, 19 (6), 386-396. 
Slater, Stanley F. and John C. Narver (1994). "Does Competitive Environment Moderate the Market Orientation-Performance Relationship”, Journal of Marketing, 58 (January), 46-55.

Wagner, Ralf (2005). "Contemporary Marketing Practices in Russia", European Journal of Marketing, 39 (1/2), 199-215. 


\section{Annex I}

\section{Types of Marketing Practices}

\section{1) TRANSACTION MARKETING}

- Your company's marketing practices are oriented toward attracting new customers.

- Your company's marketing practices are oriented toward goals relating to products and services and the company brand.

- Vis-à-vis the market in which your company interacts, the main goal is to make a profit

- Your company's contact with customers could be described as impersonal; that is, no personal contact.

- Your company's relationship with customers is characterized by individual sales.

- Your company's resources (time, people and financial resources) are invested in the adaptation of the products and services offered, promotion and distribution activities, pricing analysis (or a combination of these).

- Your company communicates (through advertising, promotions and in other ways) to the market as a whole (that is, mass market).

2) DATABASE MARKETING

- Your company's marketing practices are aimed at customer retention.

- Your company's marketing practices are oriented towards issues relating not only to products and services but also to customers.

- Vis-à-vis the market in which your company interacts, the main goal is not only profit-making, but also obtaining information for the customer database.

- Your company's contact with its customers is to some extent personalized.

- Your company's relationship with its customers could be described as occasional contact, for example, by direct mailing.

- Your company's resources (time, people and financial resources) are invested in creating and maintaining databases to improve customer communication.

- Your company communicates (through advertising, promotions and in other ways) to specific consumer segments.

\section{3) INTERACTION MARKETING}

- Your company's marketing practices are aimed at setting up cooperative relationships with customers.

- Your company's marketing practices are oriented towards goals relating to personalized relationships with customers. 
- Vis-à-vis the market in which your company interacts, the main goal is to build long-term relationships with specific customers.

- Your company's contact with its customers is personalized contact between your staff and the customer, that is, interpersonal contact.

- Your company's relationship with its customers could be described as interpersonal interaction (contact with people from your firm).

- Your company's resources (time, people and financial resources) are invested in initiating and maintaining temporary relationships with individual customers.

- Your company communicates (through advertising, promotions and in other ways) through staff in the different departments and different positions within the firm interacting personally with individual customers.

\section{4) NETWORK MARKETING}

- Your company's marketing practices are aimed at coordinating activities between the different departments of the firm and customers, suppliers, distributors and other firms with which your company interacts.

- Your company's marketing practices are oriented towards issues relating to building and maintaining relationships with suppliers, distributors and other organizations of interest to your company.

- Vis-à-vis the market in which your company interacts, the main goal is to set up relationships with other organizations in the market (for example, suppliers, distributors and organizations of interest to your company.

- Your company's contact with customers ranges from impersonal to interpersonal and takes place directly or through other companies with whom it maintains alliances or relationships of mutual interest (such as suppliers, distributors and other firms).

- Your company's relationship with its customers could be described as being through contact with your staff or the staff of other organizations with whom your company maintains relationships of mutual interest, such as suppliers, distributors and other firms.

- Your company's resources (time, people and financial resources) are invested in initiating and maintaining relationships with all agents within the company's network, such as suppliers, distributors and other companies of interest.

- Your company communicates (through advertising, promotions and in other ways) through relationships between your directors and those of other companies with which it has commercial ties. 
Table 1: Marketing practices by cluster

\begin{tabular}{|c|c|c|c|c|c|c|c|}
\hline \multirow{2}{*}{$\begin{array}{l}\text { Marketing } \\
\text { Practice }\end{array}$} & \multirow{2}{*}{$\begin{array}{l}\text { Usage } \\
\text { level }\end{array}$} & \multicolumn{2}{|c|}{ Cluster 1} & \multicolumn{2}{|c|}{ Cluster 2} & \multicolumn{2}{|c|}{ Cluster 3} \\
\hline & & Firms & $\%$ & Firms & $\%$ & Firms & $\%$ \\
\hline \multirow{3}{*}{$\begin{array}{l}\text { Transaction } \\
\text { Marketing }\end{array}$} & Low & - & - & - & - & - & - \\
\hline & Medium & 11 & 18,3 & 16 & 34 & 11 & 30,6 \\
\hline & High & 49 & 81,7 & 31 & 66 & 25 & 69,4 \\
\hline \multirow{3}{*}{$\begin{array}{l}\text { Database } \\
\text { Marketing }\end{array}$} & Low & - & - & - & - & 21 & 58,3 \\
\hline & Medium & 10 & 16,7 & 23 & 48,9 & 15 & 41,7 \\
\hline & High & 50 & 83,3 & 24 & 51,1 & - & - \\
\hline \multirow{3}{*}{$\begin{array}{l}\text { Interaction } \\
\text { Marketing }\end{array}$} & Low & - & - & - & - & 6 & 16,7 \\
\hline & Medium & 4 & 6,7 & 11 & 23,4 & 24 & 66,7 \\
\hline & High & 56 & 93,3 & 36 & 76,6 & 6 & 16,7 \\
\hline \multirow{3}{*}{$\begin{array}{l}\text { Network } \\
\text { Marketing }\end{array}$} & Low & - & - & 17 & 36,2 & 32 & 88,9 \\
\hline & Medium & 14 & 23,3 & 30 & 63,8 & 4 & 11,1 \\
\hline & High & 46 & 76,7 & - & - & - & - \\
\hline \multicolumn{2}{|c|}{ Number of firms } & 60 & & 47 & & 36 & \\
\hline Indices & Overall & \multicolumn{6}{|c|}{ Index mean by cluster } \\
\hline TM & 29 & \multicolumn{2}{|c|}{30} & \multicolumn{2}{|c|}{28} & \multicolumn{2}{|c|}{28} \\
\hline DM & 25 & \multicolumn{2}{|c|}{30} & \multicolumn{2}{|c|}{26} & \multicolumn{2}{|c|}{16} \\
\hline $\mathrm{IM}$ & 28 & \multicolumn{2}{|c|}{32} & \multicolumn{2}{|c|}{29} & \multicolumn{2}{|c|}{22} \\
\hline NM & 21 & \multicolumn{2}{|c|}{29} & \multicolumn{2}{|c|}{18} & \multicolumn{2}{|c|}{11} \\
\hline
\end{tabular}


Table 2: Psychometric Properties of Measures

\begin{tabular}{|c|c|c|c|c|c|c|c|c|c|c|}
\hline \multirow[t]{2}{*}{ Pooled sample $(n=143)$} & \multirow[t]{2}{*}{ Mean } & \multirow[t]{2}{*}{ CR } & \multicolumn{8}{|c|}{ Intercorrelations } \\
\hline & & & 1 & 2 & 3 & 4 & 5 & 6 & 7 & 8 \\
\hline 1. Customer orientation & 3.5 & 0.93 & .849 & & & & & & & \\
\hline 2. Orientation towards competitors & 3.3 & 0.89 & .455 & .850 & & & & & & \\
\hline 3. Environmental orientation & 3.1 & 0.87 & .595 & .577 & .873 & & & & & \\
\hline 4. Inter-functional coordination & 2.9 & 0.92 & .609 & .527 & .523 & .837 & & & & \\
\hline 5. Customer retention & 3.8 & 0.93 & .580 & .392 & .372 & .446 & .929 & & & \\
\hline 6. Customer recruitment & 3.6 & 0.93 & .505 & .422 & .391 & .384 & .765 & .932 & & \\
\hline 7. Turnover & 3.6 & 0.93 & .501 & .465 & .345 & .474 & .684 & .775 & .934 & \\
\hline 8. Overall profitability & 3.4 & 0.93 & .445 & .402 & .310 & .394 & .675 & .771 & .859 & .930 \\
\hline \multicolumn{11}{|c|}{ Cluster 1: Multi-marketing $(n=60)$} \\
\hline 1. Customer orientation & 4.2 & 0.90 & .784 & & & & & & & \\
\hline 2. Orientation towards competitors & 3.7 & 0.90 & .387 & .858 & & & & & & \\
\hline 3. Environmental orientation & 3.5 & 0.82 & .337 & .593 & .834 & & & & & \\
\hline 4. Inter-functional coordination & 3.6 & 0.91 & .288 & .525 & .398 & .813 & & & & \\
\hline 5. Customer retention & 4.2 & 0.84 & .507 & .410 & .246 & .346 & .850 & & & \\
\hline 6. Customer recruitment & 4.0 & 0.86 & .323 & .380 & .299 & .121 & .648 & .868 & & \\
\hline 7. Turnover & 3.8 & 0.90 & .410 & .369 & .275 & .339 & .581 & .614 & .904 & \\
\hline 8. Overall profitability & 3.7 & 0.91 & .230 & .244 & .177 & .176 & .487 & .657 & .742 & .913 \\
\hline \multicolumn{11}{|c|}{ Cluster 2: Medium-level relationship marketing $(n=47)$} \\
\hline 1. Customer orientation & 3.5 & 0.88 & .775 & & & & & & & \\
\hline 2. Orientation towards competitors & 3.2 & 0.77 & .159 & .759 & & & & & & \\
\hline 3. Environmental orientation & 3.2 & 0.80 & .616 & .154 & .826 & & & & & \\
\hline 4. Inter-functional coordination & 2.7 & 0.91 & .496 & .274 & .218 & .816 & & & & \\
\hline 5. Customer retention & 3.9 & 0.96 & .287 & .277 & .305 & .298 & .957 & & & \\
\hline 6. Customer recruitment & 3.6 & 0.93 & .224 & .258 & .218 & .191 & .765 & .934 & & \\
\hline 7. Turnover & 3.6 & 0.94 & .236 & .371 & .104 & .280 & .573 & .774 & .941 & \\
\hline 8. Overall profitability & 3.4 & 0.93 & .278 & .347 & .124 & .293 & .643 & .746 & .903 & .935 \\
\hline \multicolumn{11}{|c|}{ Cluster 3: Transactional marketing $(n=36)$} \\
\hline 1. Customer orientation & 2.3 & 0.87 & .753 & & & & & & & \\
\hline 2. Orientation towards competitors & 2.7 & 0.86 & .018 & .823 & & & & & & \\
\hline 3. Environmental orientation & 2.1 & 0.68 & .127 & .569 & .749 & & & & & \\
\hline 4. Inter-functional coordination & 1.9 & 0.77 & .513 & .413 & .507 & .680 & & & & \\
\hline 5. Customer retention & 3.0 & 0.95 & .568 & .151 & -.017 & .322 & .953 & & & \\
\hline 6. Customer recruitment & 3.1 & 0.95 & .433 & .304 & .218 & .487 & .674 & .952 & & \\
\hline 7. Turnover & 3.1 & 0.93 & .412 & .411 & .229 & .525 & .724 & .792 & .931 & \\
\hline 8. Overall profitability & 2.9 & 0.91 & .327 & .392 & .224 & .440 & .729 & .795 & .858 & .917 \\
\hline
\end{tabular}


Table 3: Model estimation

\begin{tabular}{|c|c|c|c|c|}
\hline & Pooled & Cluster 1 & Cluster 2 & Cluster 3 \\
\hline \multicolumn{5}{|l|}{ Structural relationships } \\
\hline Customer orientation $\rightarrow$ Customer retention & $.48 * *$ & $.41 * *$ & .03 & $.57^{* *}$ \\
\hline Customer orientation $\rightarrow$ Customer recruitment & .04 & -.06 & .06 & -.06 \\
\hline Orientation towards competitors $\rightarrow$ Customer retention & $.15^{*}$ & $.23 * *$ & .19 & $.27^{* *}$ \\
\hline Orientation towards competitors $\rightarrow$ Customer recruitment & $.12^{*}$ & $.17^{* *}$ & .06 & .07 \\
\hline Environmental orientation $\rightarrow$ Customer retention & -.06 & -.08 & $.22^{*}$ & $-.27 * *$ \\
\hline Environmental orientation $\rightarrow$ Customer recruitment & .07 & $.15^{* *}$ & -.04 & .07 \\
\hline Inter-functional coordination $\rightarrow$ Customer retention & .10 & $.14^{* *}$ & $.18^{* *}$ & .06 \\
\hline Inter-functional coordination $\rightarrow$ Customer recruitment & -.05 & $-.24 * *$ & -.07 & $.26 * *$ \\
\hline Customer retention $\rightarrow$ Customer recruitment & $.69 * *$ & $.65^{* *}$ & $.77^{* *}$ & $.62 * *$ \\
\hline Customer retention $\rightarrow$ Turnover & $.22 * *$ & $.32 * *$ & -.04 & $.35 * *$ \\
\hline Customer retention $\rightarrow$ Overall profitability & .06 & -.07 & $.21 * *$ & $.17^{* *}$ \\
\hline Customer recruitment $\rightarrow$ Turnover & $.61^{* *}$ & $.41 * *$ & $.81^{* *}$ & $.56 * *$ \\
\hline Customer recruitment $\rightarrow$ Overall profitability & $.22 * *$ & $.36 * *$ & -.05 & $.26 * *$ \\
\hline Turnover $\rightarrow$ Overall profitability & $.64 * *$ & $.57 * *$ & $.82 * *$ & $.53 * *$ \\
\hline \multicolumn{5}{|l|}{ Average communality } \\
\hline Customer orientation & .72 & .61 & .60 & .57 \\
\hline Orientation towards competitors & .72 & .74 & .58 & .68 \\
\hline Environmental orientation & .76 & .70 & .68 & .56 \\
\hline Inter-functional coordination & .70 & .66 & .67 & .46 \\
\hline Customer retention & .86 & .72 & .91 & .91 \\
\hline Customer recruitment & .87 & .75 & .87 & .91 \\
\hline Turnover & .87 & .82 & .88 & .87 \\
\hline Overall profitability & .86 & .83 & .87 & .84 \\
\hline \multicolumn{5}{|c|}{$\begin{array}{l}\text { Variance of dependent variables explained in the model } \\
\text { (percent) }\end{array}$} \\
\hline Customer retention & 36 & 33 & 18 & 39 \\
\hline Customer recruitment & 61 & 48 & 59 & 55 \\
\hline Turnover & 62 & 44 & 60 & 69 \\
\hline Overall profitability & 77 & 62 & 84 & 78 \\
\hline
\end{tabular}

** significant at $p<.05,{ }^{*}$ significant at $p<.10$ 
Figure 1: Model estimation for the pooled sample

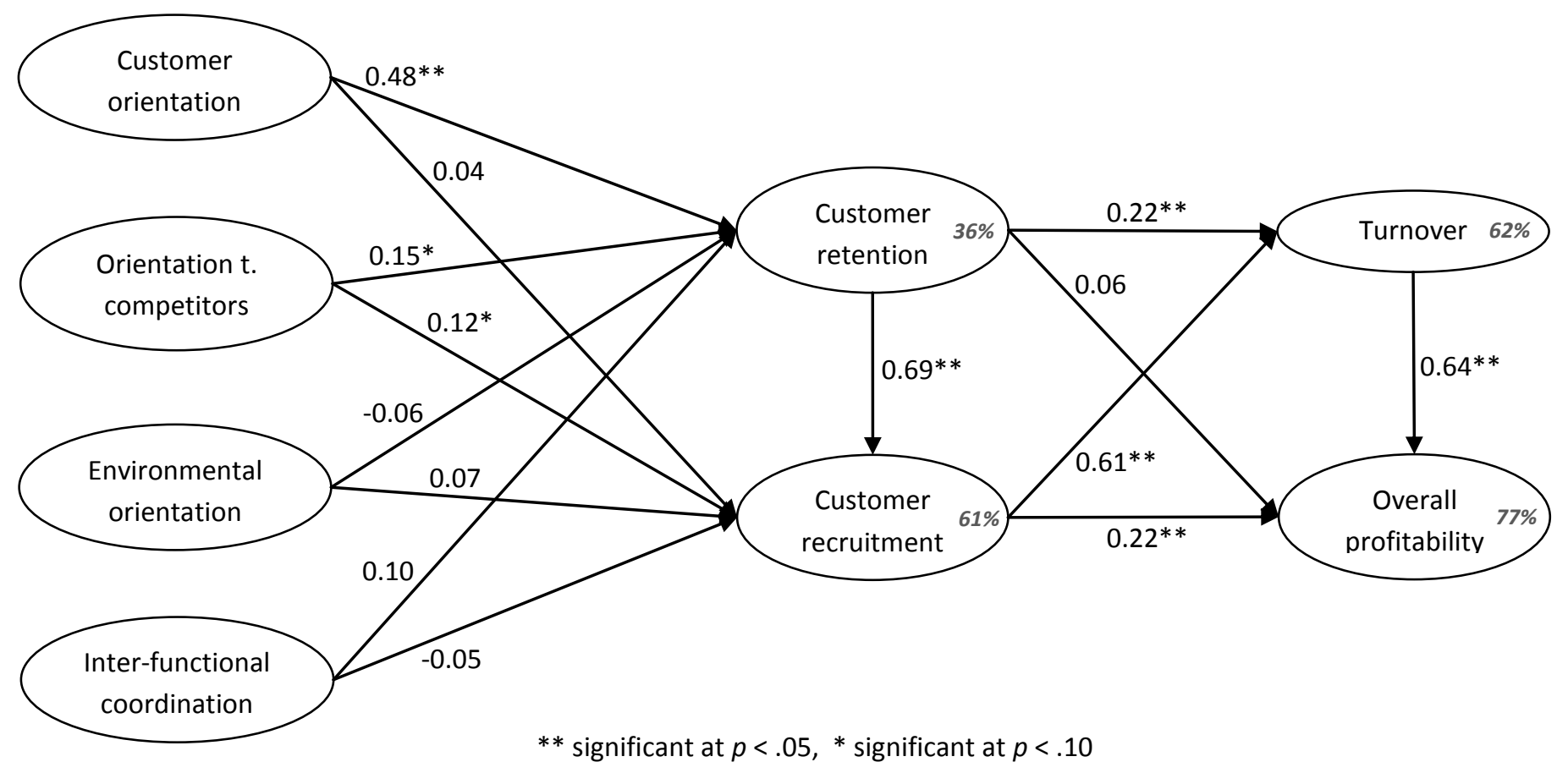

